\title{
3D Printed Stirling Engines for Education of Machine Design and Analysis
}

\author{
By Don Clucas* \\ Stefanie Gutschmidt
}

The recent proliferation of low to medium cost additive manufacturing equipment opens a doorway to using the technology for aiding the education of many engineering principles. Stirling cycle engines are highly complex thermodynamic machines that, if delved into, demonstrate many mechanical engineering disciplines. Importantly fully functional engines, using safe hot and cold water as their energy source, can be made by polymer additive manufacture using commonly available materials and printing machines. This process somewhat negates the need to invest in high cost laboratory demonstration equipment. It also allows remote and poorly funded institutions or individuals to work with live equipment. This publication will demonstrate the use of additive manufactured Stirling Engines for effective teaching in creative design, optimization product development, thermodynamics, mechanics, computational fluid dynamics, finite element analysis, live data acquisition, material science and additive manufacture.

Keywords: $3 D$ Printing, Additive Manufacturing, Engineering Design, Mechanism Analysis, Stirling Engine

\section{Introduction}

Stirling Cycle Engines

Stirling engines operate on a closed thermodynamic cycle and are powered by heat supplied to the hot heat exchanger $T_{h}$, Figure 1, and heat removed by the cold heat exchanger $T_{c}$. A displacer moves the internal gas, the working fluid, between hot and cold heat exchangers and the resulting pressure gradient acts on the power piston. The displacer and power pistons are generally linked by a mechanism having approximately a $100^{\circ}$ phase angle. According to the Carnot efficiency equation (1) the performance of the engine depends on the temperature difference, $T_{h}-T_{c}$.

$$
\eta=1-\frac{T_{c}}{T_{h}}
$$

\footnotetext{
* Senior Lecturer, University of Canterbury, New Zealand.

${ }^{\dagger}$ Senior Lecturer, University of Canterbury, New Zealand.
} 
Figure 1. Typical Gamma and Beta Configuration Stirling Engines for Use with High Temperature Heat Exchangers

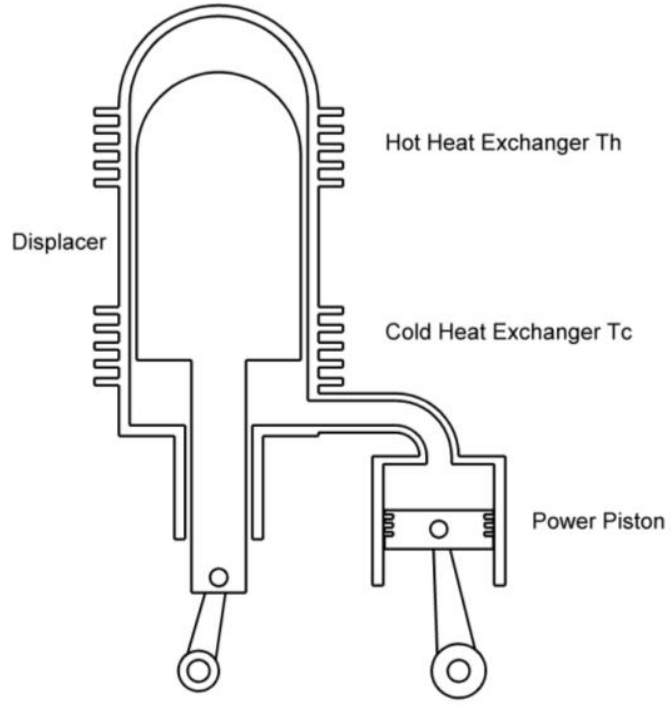

Gamma

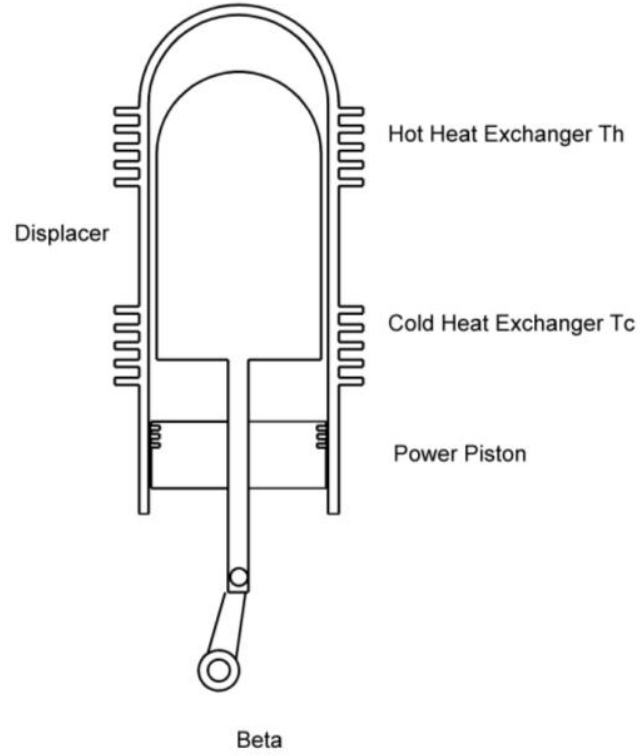

$T_{c}$ is generally closely linked to ambient temperature but $\mathrm{T}_{\mathrm{h}}$ can approach the material limits of the hot heat exchanger. High performance engines, with high power density, have the heat supplied by a flame or from a solar concentrator (Watanabe, 2007), and can operate hot heat exchanger temperatures exceeding $800^{\circ} \mathrm{C}$ (Jones, 2007). However, unlike internal combustion engines, the maximum heat input temperature, $T_{h}$, can be as low as hand temperature (Senft, 1991). Some designers have operated engines with $T_{h}-T_{c}$ less than $1^{\circ} \mathrm{C}$ (Senft, 1991). Engines operating with $T_{h}<100^{\circ} \mathrm{C}$ are known as Low Temperature Difference (LTD) Stirling engines. Commercial use of LTD low efficiency engines, using low grade geothermal or solar energy, have been studied (Gaynor, 2008; Kongtragool, 2003) but there has been limited commercial application. High performance engines use metal heat exchangers made from a high temperature resistant grade of stainless steel such as Sandvik 253MA (Jones, 2007). It has been shown that LTD engines, however, can use 3D printed polymer heat exchangers and use clean and safe hot and cold water as a heat source and sink (Clucas, 2014). LTD engine heat exchangers generally take the form of two aluminum plates, Figure 2. 
Figure 2. Typical LTD Stirling Engine

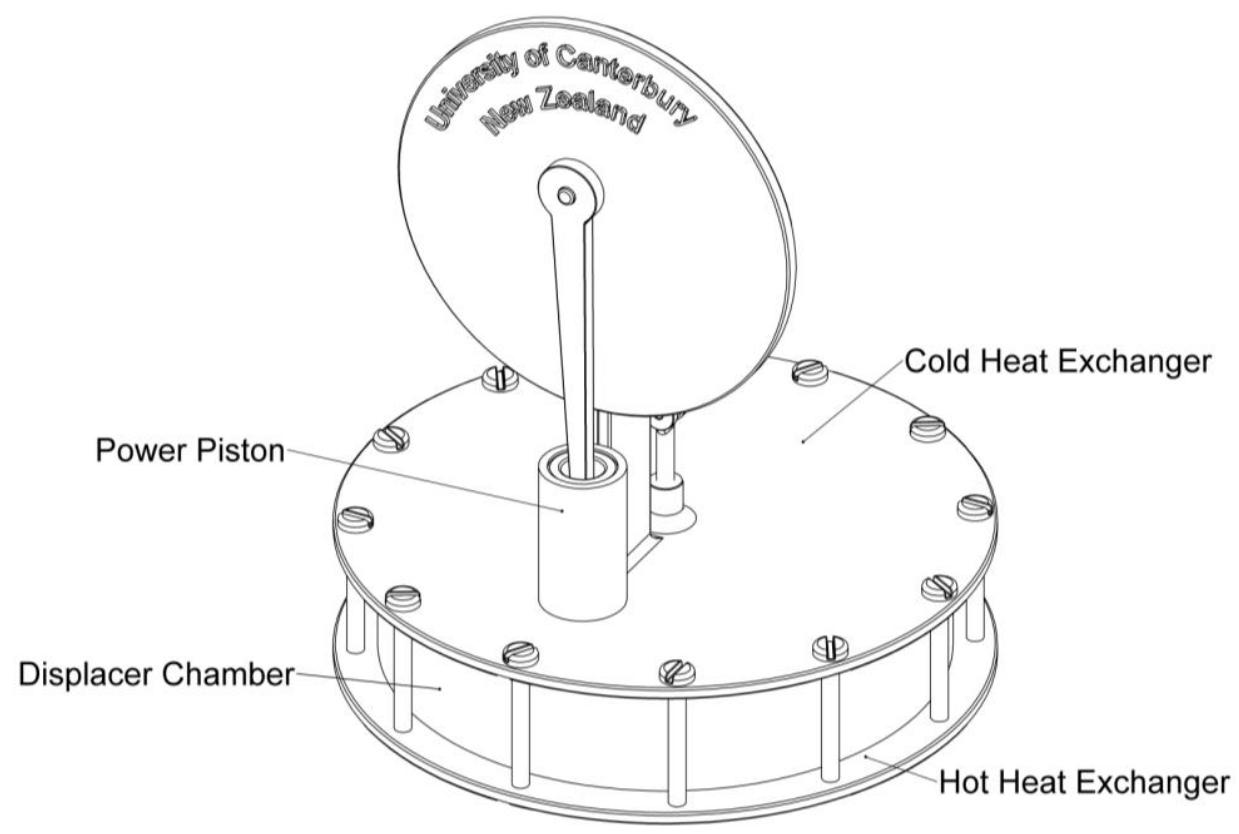

The lures of high efficiency, quiet operation, optional heat source (including solar), low maintenance and multiple possible engine layouts have attracted many inventors, developers and investors over the years. Despite an estimated excess of $\$ 1$ billion invested into the engine, system and market development the only engines that could be identified as current in serial production for a domestic market are model engines used as curiosities.

\section{Additive Manufacture}

Also commonly known as 3D printing (Huang, 2015) is a manufacturing process that generally involves building a model by laying down slices or layers of build material according to the shape of the current cross section. The part complexity can be extreme when compared with traditionally manufactured parts made by subtractive or molding processes so parts that would be impossible before, like complex heat exchanger geometry, is now possible.

Until 2009 3D printers were relegated as a piece of specialized equipment and were generally used for rapid prototyping. The cost of a machine could exceed $\$ 100,000$ and so was out of the reach of the domestic users. In 2009 a patent owned by Stratasys, Inc. (Crump, 1992) that monopolized the production and sales of machines operating on the Fused Deposition Modeling (FDM), Figure 3, expired. This opened the door for enthusiasts and manufacturers to develop printers that produce parts, of acceptable quality, for home and school use and that cost less than $\$ 1,000$ (Huang, 2015). Over the last five years there has been a rapid rise of the number of printers on the market (Huang, 2015). 'The unit sales of industrial AM systems (unit price $>\$ 5,000$ ) increased by $19.3 \%$ to 7,771 units in 2012, while the unit sales of 3D personal printers (unit sale price $<\$ 5,000$ increased by $46.3 \%$ to 35,508 units in the same year.' This does not include the 
uptake aided by file sharing organizations such as Reprap that freely circulate 3D printer designs on the internet for enthusiasts to make their own machines, often using parts made on a friend's 3D Printer. This has also been supported by a rapid rise of the number of model files that can be downloaded from the Internet. Sites such as Thingiverse offer thousands of models for free download, allowing people without computer aided design skills to make parts of complexity that otherwise would require a skilled designer. Today, many secondary schools and tertiary institutions in New Zealand have at least one FDM printer.

Figure 3. FDM 3D Printing Process

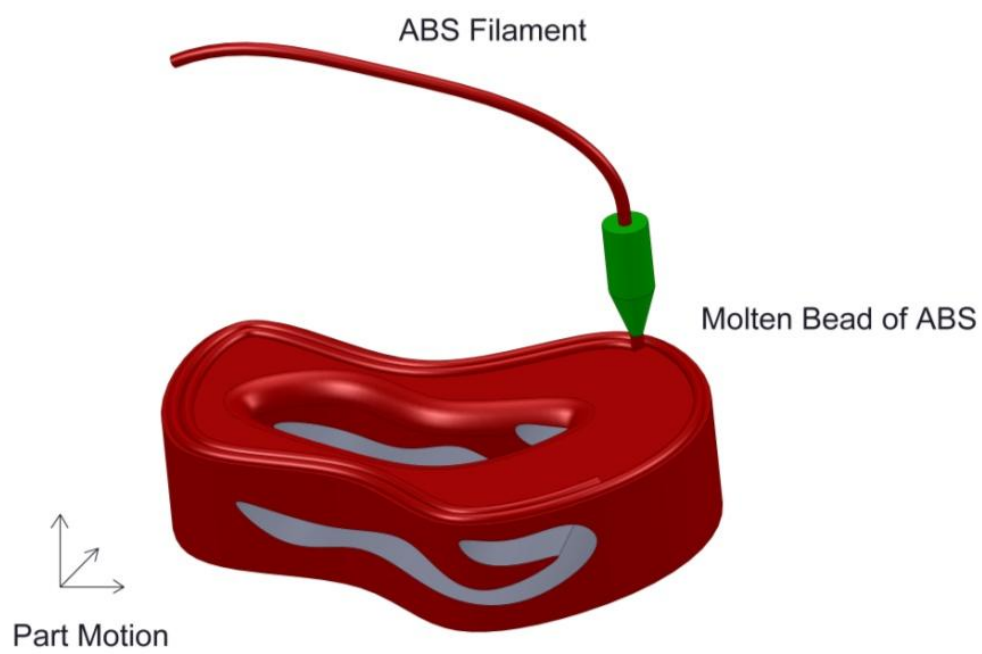

\section{Laboratory Teaching Aids}

Live laboratory equipment, especially those related to thermodynamic engines, can be cost prohibitive for many teaching institutions. Not only the equipment is expensive but also the cost of work safe lab space to house it is. Also health and safety, noise, fumes and dealing with combustible fuels etc. can hamper the use of internal or external combustion engines, especially as health and safety regulations and considerations in teaching environments is understandably becoming more stringent.

This work describes several examples of using low cost additive manufacturing equipment to make safe and affordable laboratory demonstration equipment.

\section{Options for Education}

The complexity of the demonstration would be tailored to suit the students' academic level. For example:

- Junior high school

- Observe the operation of a heat engine

- Senior high school 
- Explain the operation of the engine

$\circ$ Observe the effects of heating and cooling a gas and how the pressure variations can be used to rotate a shaft

- Consider the mechanics of operation

$\circ$ Measure $T_{h}, T_{c}$ and the shaft speed with an optical tachometer and observe how the temperature difference affects the machine performance

- Adjust other parameters and observe and explain possible different results

- Tertiary education (undergraduate)

- Using Arduino or similar electronics along with e.g. LabView software for acquiring real time data from the engine

- Obtain a pressure/volume diagram for the engine

- Measure loads on selected parts of the engine and monitor deflections by using strain gauges

- Mechanical and dynamic synthesis of the machine

- Creative and innovative design

- Tertiary education (postgraduate)

$\circ$ Detailed analysis and design of a part or subsystem

- Optimization of machine elements and/or the entire engine

\section{Thermodynamic Analysis}

Figure 4 shows an example of a LTD Stirling engine specifically designed for additive manufacture and educational purposes. It sits on a printed container of hot water and cold water fills the space on the upper side of the displacer chamber. A printed diaphragm expands and compresses the air inside the displacer chamber and the resulting forces act on a beam connected to the engine shaft via a connecting rod and crank. It incorporates options for shaft position sensing, cycle pressure measurement, temperature measurement $T_{h}$ and $T_{c}$ and the ability to adjust key parameters associated with an operating Stirling engine such as a diaphragm (piston) stroke, displacer stroke and phase angle between the compression/expansion from the diaphragm and the displacer motion. 
Figure 4. 3D Printed LTD Stirling Engine for Education

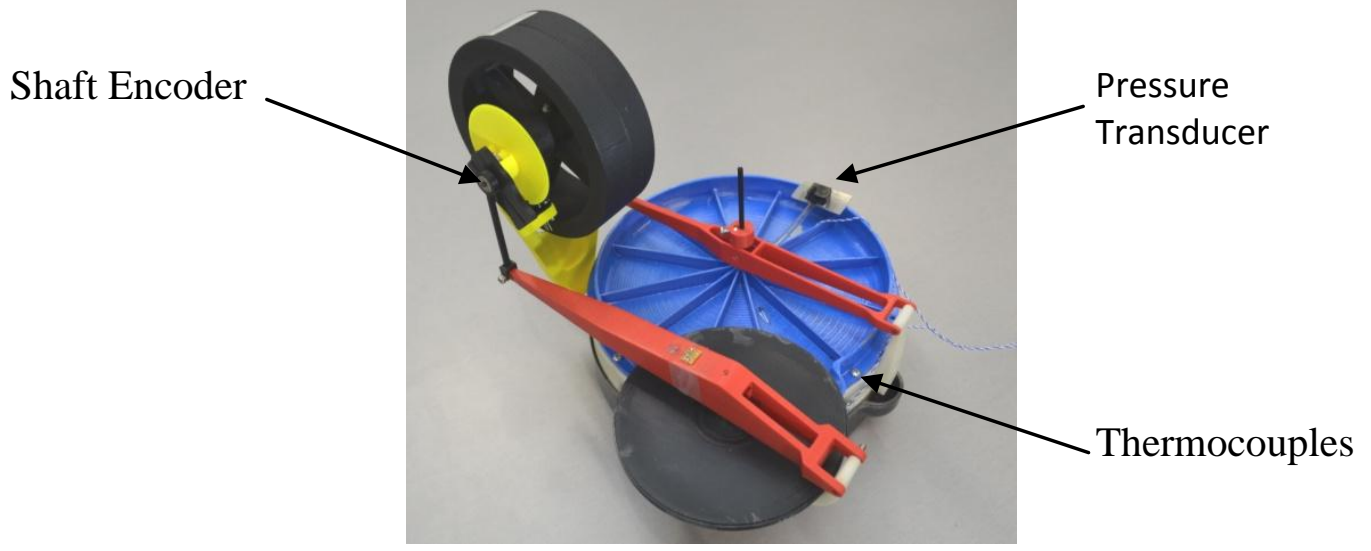

Taking these measurements, the students can observe, determine and analyze the effects of the changing parameters.

Students might perform a 'run down' test, for example, where they can observe the effect on engine performance of changing the hot and cold heat exchanger temperature difference, Figure 5.

Figure 5. Example of Measured Shaft Speed Run during a Down Test of a LTD Stirling Engine

\section{LTD Stirling Engine Run Down Test}

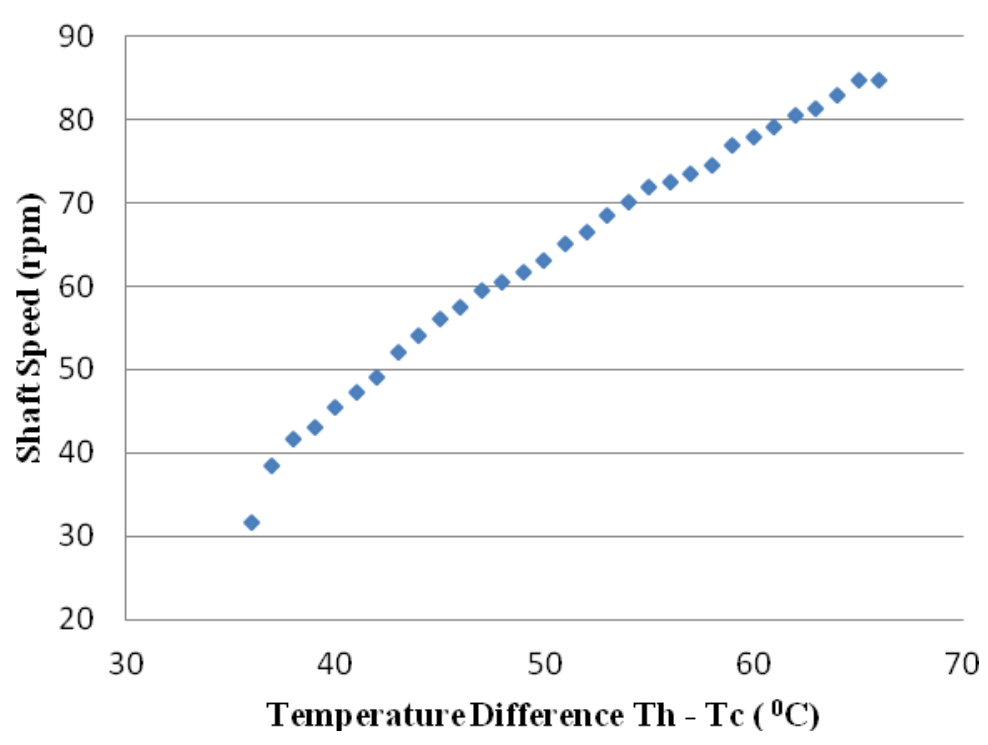

\section{Mechanical Analysis}

In 2014, the Mechanical Engineering program included the Stirling Engine project as an educational tool in the course Dynamics and Vibration (ENME203, (Gutschmidt, 2014)), taught in the second year. The course content includes the mechanical disciplines kinematics, dynamics and vibrations, and is supplemented 
and supported by suitable real-life applications and examples (Gutschmidt, 2014). At the completion of the course the students are expected to be able to master the following engineering tasks:

1) Understanding how to describe real-life observations (related to things in motion) with the help of mathematic-mechanical expressions.

2) Ability to derive equations of motion of mechanical systems (machine elements and machines) by taught kinematic and dynamic methods.

3) Ability to analyze mechanical systems in motion (linear behavior only).

4) Ability to independently apply methods and analyses to a wider and yetunknown spectrum of real-life engineering problems.

As part of the assessment structure, students worked on a small project (in groups of four), typically scheduled at the beginning of the second half of the course, after the completion of teaching the Kinematics and Dynamics content. The subject of the project changes from year to year and in 2014 the Stirling Engine was chosen. The details of the project are explained in lecture and all necessary data are made available for students via the university's onlinecourse system LEARN (Canterbury, 2014).

\section{Project Description}

The project tasks as given to the students included the derivations of kinematic and dynamic expressions. The formulation of the final governing equation of motion was one of the key outcomes requested by the student teams and are presented here. Although numerical integration methods were not taught in the Dynamics and Vibration course, the opportunity to solve the governing equation numerically was given. Numerical integration methods have been taught in a mathematical paper (EMTH271, (Blanck, 2014)) which students took in the same semester.

All parameters as well as an initial suggestion for a simplified model were given to the students. Figure 6 depicts the CAD model and schematic sketch of the 3D printed Stirling engine.

Figure 6. CAD Model (Left) and Schematic Sketch (Right) of the 3D Printed Stirling Engine
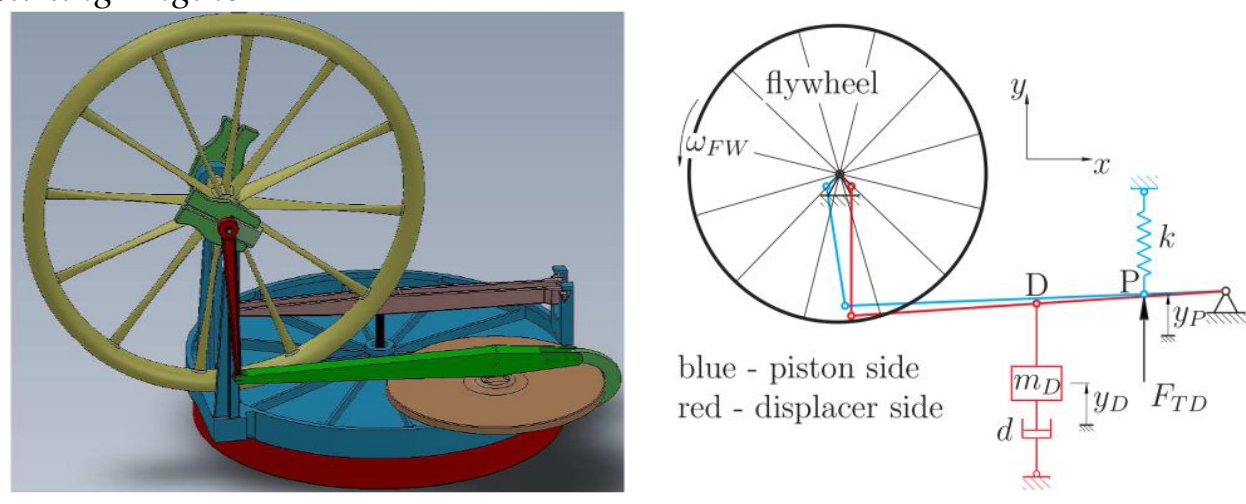
The pressure profile (Figure 7) had been measured and was taken to model the input signal of the engine.

Figure 7. Pressure Profile over One Cycle; Red Circles: Measured, Blue Solid Line: Polynomial Fit

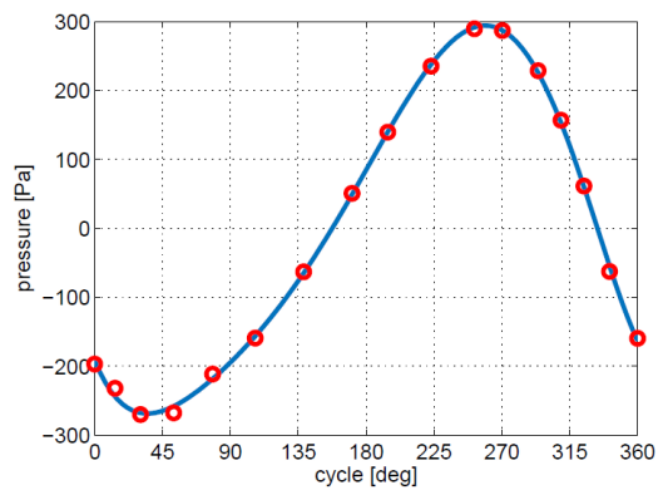

Analysis and Results

The relationship of the piston and displacer mechanisms can be described by the kinematics of a four-bar mechanism (Myszka, 2012). The piston and displacer mechanisms are approximately $100^{\circ}$ out of sync, with the displacer being ahead of the piston. The mathematical descriptions of both trajectories are depicted in Figure 8 for one complete cycle.

Figure 8. Piston and Displacer Trajectories in Dependency of the Flywheel Motion

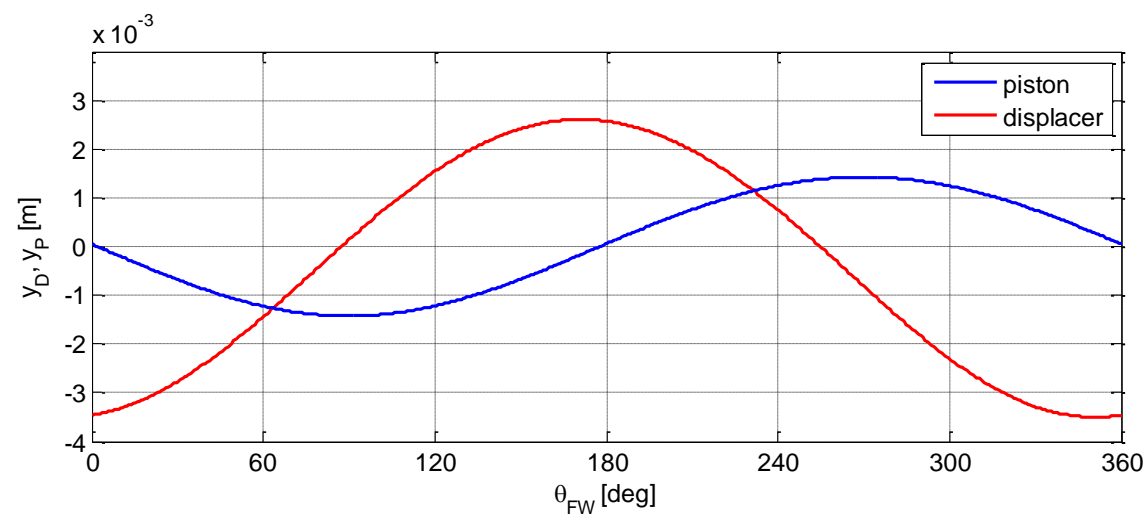

Additional kinematic quantities, such as the velocity $\boldsymbol{v}_{D}$ and acceleration $\boldsymbol{a}_{D}$ of the displacer, are needed to formulate the equation of motion of the Stirling Engine. The course curriculum includes a trigonometric vector as well as graphical methods to derive velocity and acceleration relations of rigid bodies. The following set of equations use the vector formulation in the space-fixed reference frame. The notation is supported by the schematic sketch in Figure 9. 
Figure 9. Sketch of Displacer Mechanism with Kinematic Symbols

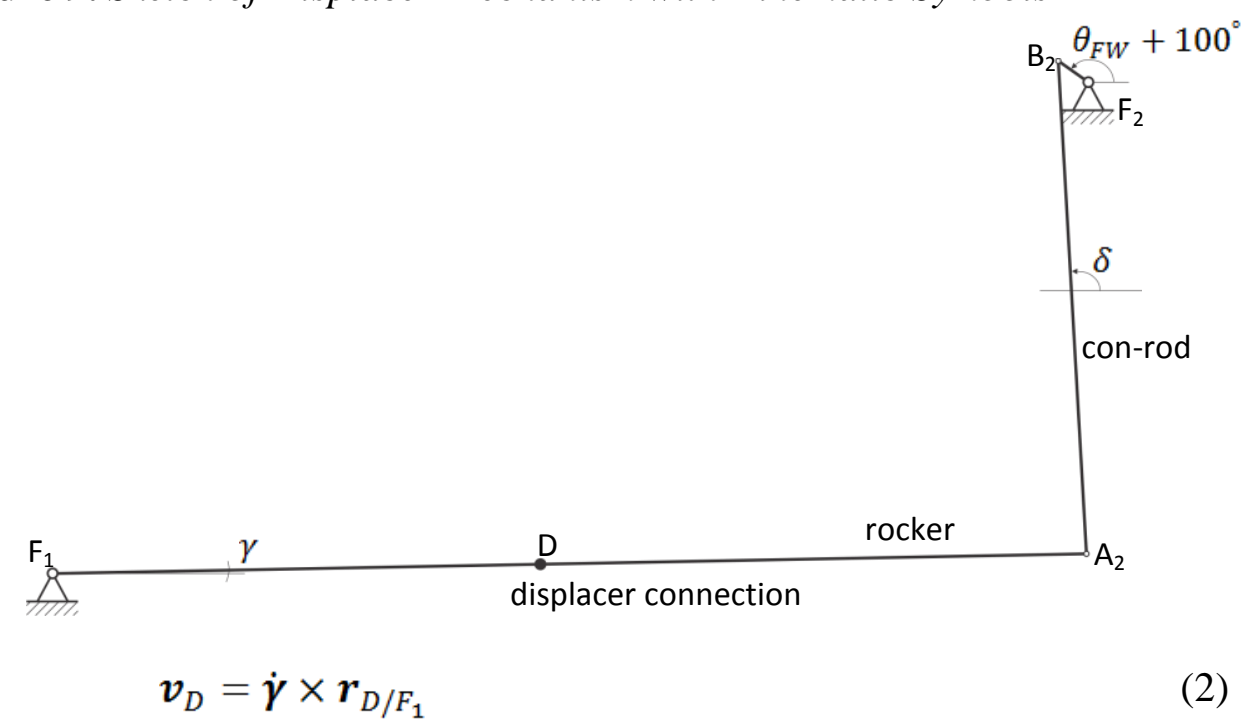

Equation (2) shows the velocity of the displacer. While the position vector $\boldsymbol{r}_{D / F_{1}}$ of point $\mathrm{D}$ with respect to $\mathrm{F}_{1}$ is known, the initially unknown angular velocities $\dot{\gamma}$ and $\dot{\boldsymbol{\delta}}$ of rocker and con-rod are found by equating

$$
\boldsymbol{v}_{A_{2}}=\dot{\boldsymbol{\gamma}} \times \boldsymbol{r}_{A_{2}}
$$

and

$$
v_{A_{2}}=v_{B_{2}}+\dot{\delta} \times r_{A_{2 / B_{2}}}
$$

Equation (3) describes the velocity of point $\mathrm{A}_{2}$ by means of a pure rotation about point $F_{1}$, while (4) is the velocity of point $A_{2}$, when composed of the motion of point $B_{2}$ and the relative motion of the con-rod with respect to point $B_{2}$. The velocity of point $B_{2}$ is also described by a rotation about point $F_{2}$

$$
\boldsymbol{v}_{B_{2}}=\omega_{F W} \times r_{B_{2}}
$$

where $\boldsymbol{\omega}_{F W}=\dot{\boldsymbol{\theta}}_{F W}=\left[0,0, \dot{\theta}_{F W}\right]^{T}$ is the angular velocity vector of the flywheel.

Since the displacer is modeled by an additional mass (Figure 6, right), also the vertical acceleration component of point $\mathrm{D}$ is required, for which a similar process as for the velocity is followed. The absolute acceleration of point $D$ is expressed by

$$
\boldsymbol{a}_{D}=\ddot{\gamma} \times \boldsymbol{r}_{D / F_{1}}+\dot{\gamma} \times\left(\dot{\gamma} \times \boldsymbol{r}_{D / F_{1}}\right),
$$

the first term being the tangential and the second being the radial components of the vector. Again, the initially unknown angular accelerations of rocker $\ddot{\gamma}$ and con-rod $\ddot{\boldsymbol{\delta}}$ are obtained by equating

$$
a_{A_{2}}=\ddot{\gamma} \times r_{A_{2}}+\dot{\gamma} \times\left(\dot{\gamma} \times r_{A_{2}}\right)
$$

and

$$
\boldsymbol{a}_{A_{2}}=\boldsymbol{a}_{B_{2}}+\ddot{\boldsymbol{\delta}} \times \boldsymbol{r}_{A_{2} / B_{2}}+\dot{\boldsymbol{\delta}} \times\left(\dot{\boldsymbol{\delta}} \times \boldsymbol{r}_{A_{2} / B_{2}}\right),
$$

where 


$$
\boldsymbol{a}_{B_{2}}=\dot{\boldsymbol{\omega}}_{F W} \times \boldsymbol{r}_{B_{2}}+\boldsymbol{\omega}_{F W} \times\left(\boldsymbol{\omega}_{F W} \times \boldsymbol{r}_{B_{2}}\right) .
$$

All quantities, apart from the flywheel, are thus either known or expressed in terms of the free flywheel variables $\theta_{F W}, \dot{\theta}_{F W}, \ddot{\theta}_{F W}$.

The coupled equation of motion is derived based on Newton's $2^{\text {nd }}$ Law (Newton, 1687). Figure 10 depicts the free-body diagrams of all relevant parts of the Stirling engine, namely, rockers, con-rods, displacer as well as the flywheel. Only horizontal and vertical motions are considered within the plane.

Figure 10. Free-body Diagrams of Relevant Parts of the Stirling Engine; a) Rockers, b) Con-rods, c) Displacer, d) Flywheel; Blue Color: Piston Side, Red Color: Displacer Side (c.f. Figure 6, Right)

a)

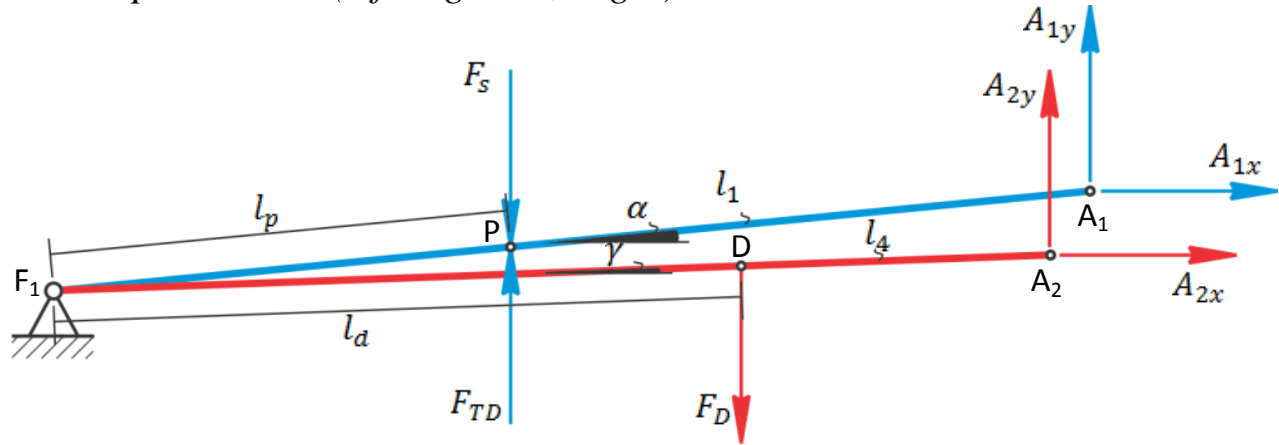

b)
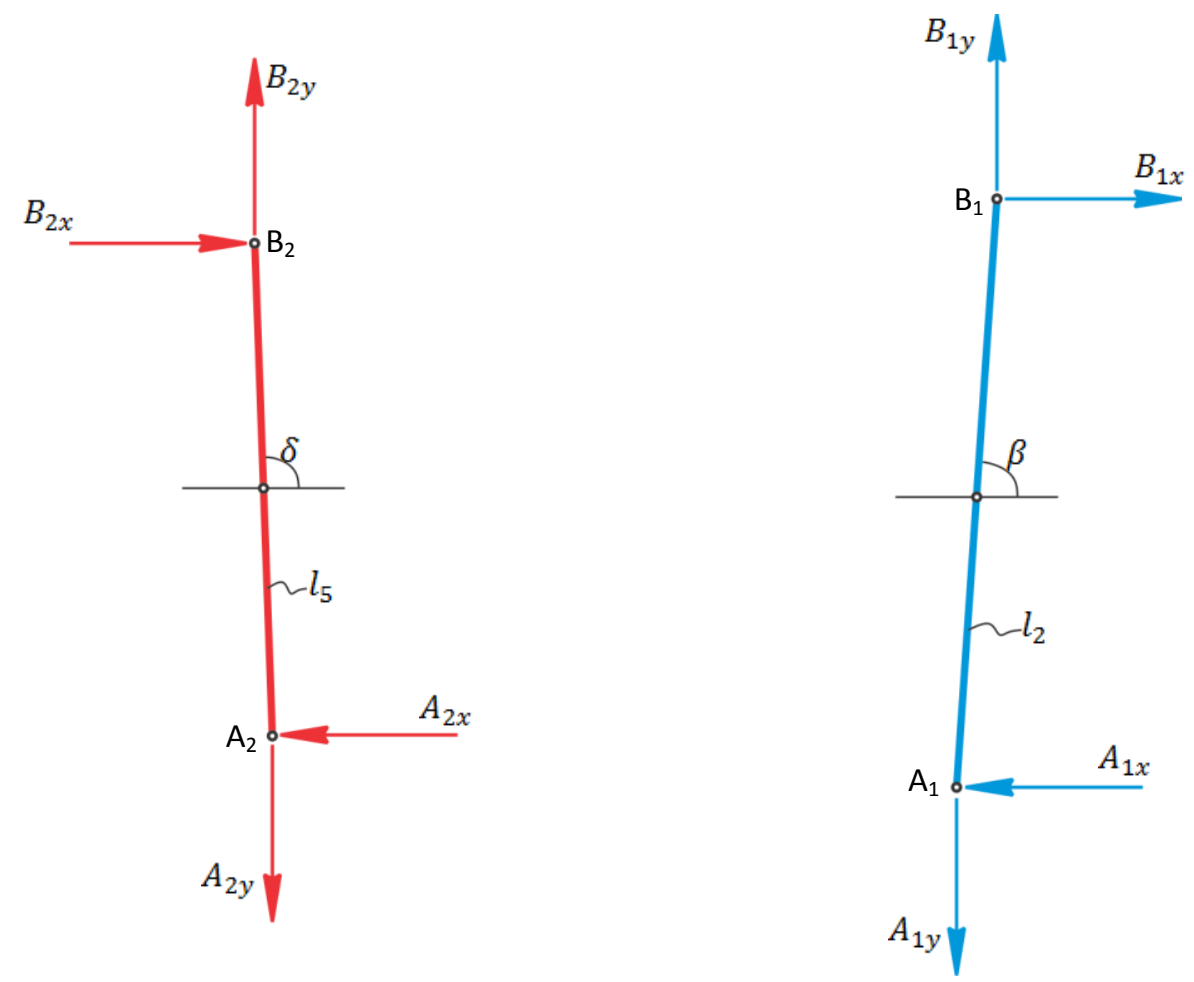
c)

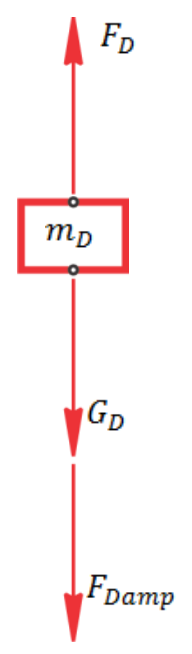

d)

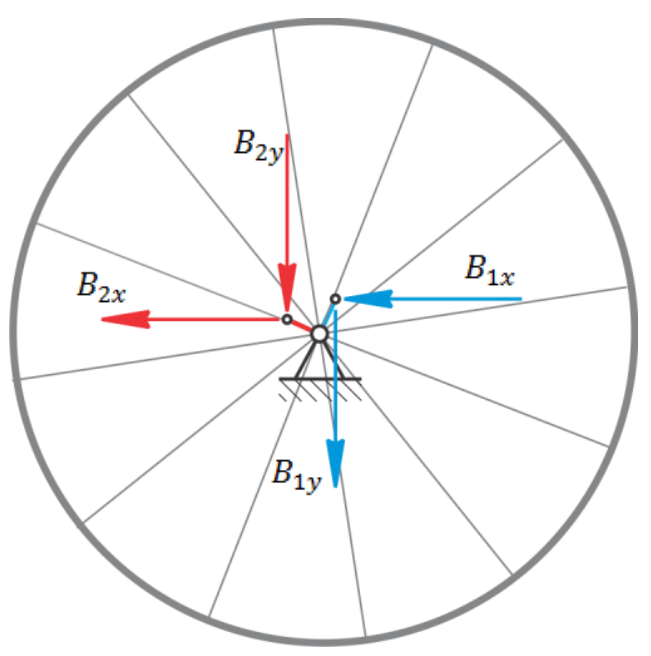

The governing equation that describes the motion of the flywheel according to the free-body diagrams (Figure 10) and the given pressure profile (Figure 7) is

$$
\begin{aligned}
& I_{F W} \ddot{\theta}_{F W}=\left(m_{D} \ddot{y}_{D}+d_{D} \dot{y}_{D}+m_{D} g\right) \\
& \cdot \frac{l_{d} l_{6}}{l_{4}}\left\{\frac{\tan \delta \cos \left(\theta_{F W}+100^{\circ}\right)-\sin \left(\theta_{F W}+100^{\circ}\right)}{\tan \gamma+\tan \delta}\right\} \\
& +\left(F_{T D}-F_{s}\right) \frac{l_{p} l_{3}}{l_{1}}\left\{\frac{\sin \theta_{F W}-\tan \beta \cos \theta_{F W}}{\tan \beta-\tan \alpha}\right\} .
\end{aligned}
$$

Without showing the details of the derivation of (10), this simple model includes relevant inertia, damping and restoring mechanisms subject to the measured thermo-dynamic actuation (c.f. Figure 7). The thermo-mechanical interactions however are not included. The dynamics, as can be seen from (10), describes a parametrically excited system, where $F_{T D}$ is the thermo-dynamic force $F_{T D}=p A$ ( $A$ being the cross-sectional area of the piston) and $F_{S}$ is the restoring force at the piston, $F_{S}=k y_{P}$ (c.f. Figure 6). Note, that (10) contains two terms dependent on $\ddot{y}_{D}$ and $\dot{y}_{D}$. The velocity, $v_{D}=\dot{y}_{D}=\boldsymbol{v}_{D} \cdot \boldsymbol{u}_{y}$, and vertical acceleration, $a_{D}=\ddot{y}_{D}=\boldsymbol{a}_{D} \cdot \boldsymbol{u}_{y}$, of point $\mathrm{D}$ are functions of known parameters and the free flywheel variables $\theta_{F W}, \dot{\theta}_{F W}, \ddot{\theta}_{F W}$, which are previously defined by (2) and (6), respectively. ( $\boldsymbol{u}_{y}$ describes the unit vector in the vertical direction.) An initial set of parameters were given, with which students could solve (10) numerically. 
Figure 11. Simulated Angular Velocity of the Flywheel Depicted over the First Cycle

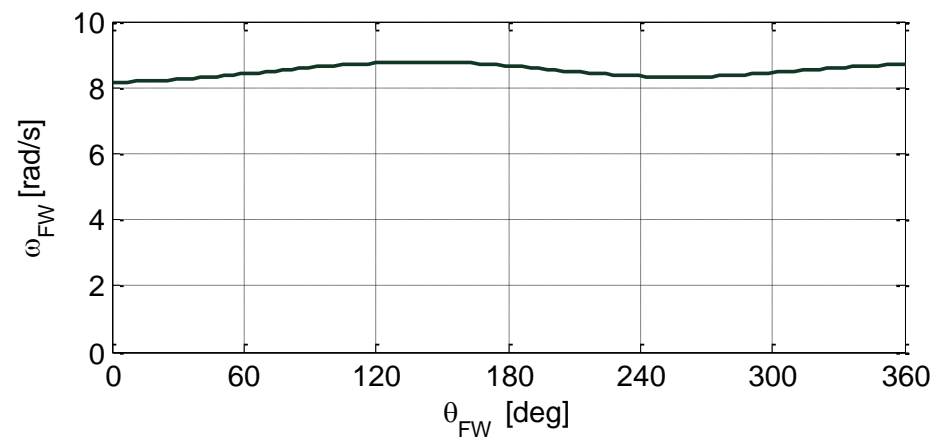

Figure 11 shows the numerical solution of (10) for the selected parameters, namely the motion of the flywheel over the first cycle. Note, that (10) is a highly nonlinear equation for which a linear analysis, as taught to $2^{\text {nd }}$ year students, is insufficient. Thus, a nonlinear analysis was left to the postgraduate students and its results, together with a more detailed derivation of the governing equation, with focus on the performance of the Stirling engine (theoretically and experimentally) will be published elsewhere.

\section{Expected and Actual Learning Outcomes}

Expected learning outcomes included that students would be able to deploy all kinematic relations based on methods covered during the course. This included thinking of a suitable (simple) model and associated assumptions. Furthermore, students were expected to draw all relevant free-body diagrams and to formulate the governing equation of motion, identifying known and unknown parameters as well as expressing equations in terms of the free variable $\theta_{F W}$.

The actual learning outcomes have matched the expected ones in the area of free-body diagrams and formulating kinetic expressions. Additional help was required for parts like deriving kinematic relationships as well as codifying the numerical integration with software package e.g. Matlab.

Overall, however, the actual learning outcomes have also exceeded the expected results. Students recognized the importance of the manifold, interdisciplinary subjects of their engineering program. With students, being able to work in teams of three or four, they found their "place" of responsibility and expertise in most cases. The project offered a holistic engineering approach to solve a design problem. An invaluable advantage of this integration of a real machine into the engineering program at this stage was the transfer of knowledge that has happened by students that were able to predict the motion as well as to observe its performance. Rather than educating students to "do engineering" this project has majorly contributed to students to "become engineers". Other direct, valuable learning outcomes included that of team work, responsibility within group and project and professional communication (oral, written). 


\section{Subsystem Design}

The $\mathrm{BE}(\mathrm{Hons})$ program of Mechanical Engineering at the University of Canterbury requires for students in their final year (year 4) to complete 3 compulsory subjects and 4 electives. One elective option is a single semester Independent Course of Study (ICOS). In this case students with a GPA >7 (out of 9) may choose to complete an individual research project. The projects are put forward by academics wishing to have preliminary research results on a specific topic. This may be to aide or initiate post graduate work or perform preliminary research for fleshing out potential post-graduate projects. It is also useful for vetting potential post graduate students. In 2014, 15 students out of a cohort of 94 chose an ICOS of their interest.

Two ICOS projects related to the design and development of the LTD Stirling engines were offered in 2014, both requiring the research and development of a particular aspect of the LTD engine. The projects were:

- Investigating the feasibility for using 3D printed polymer bearings for the main shaft support. Until the completion of that project there had been no published fully $3 \mathrm{D}$ printed thermodynamic engines. The challenge which prevented this breakthrough for LTD Stirling Engines, was the issue of $3 \mathrm{D}$ printing low friction bearings. We developed a bearing test rig, Figure 12, which incorporated a data acquisition system to measure the friction performance of various bearing designs. Ultimately a fully 3D printed Stirling engine was developed, tested and then the design/printing files were published open source for people to replicate at www.projectstoprint.com.

Figure 12. Student Designed and 3D Printed Bearing Drag Test Apparatus

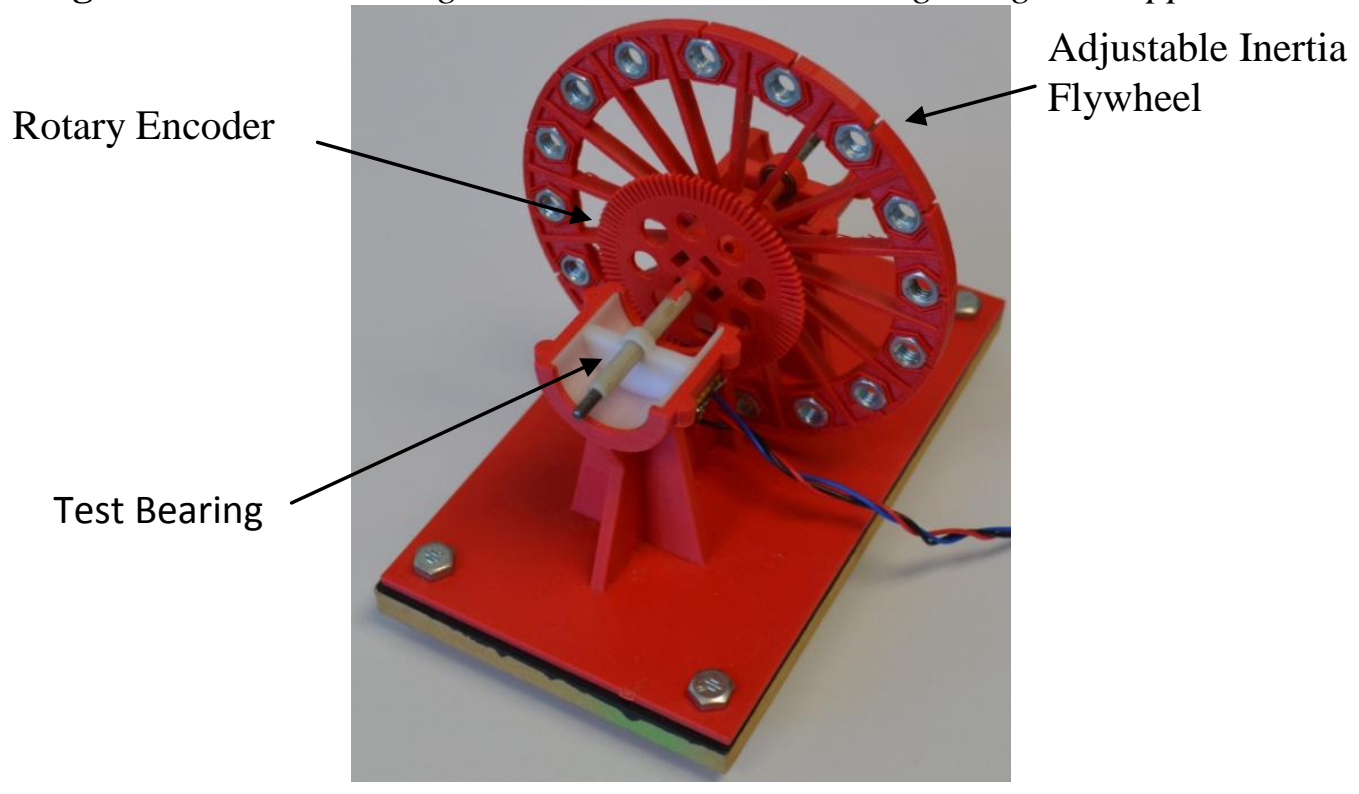

- Diaphragm Optimization. The performance of the LTD Stirling Engine is greatly affected by the sealing efficiency and drag of the item 
performing the role of the expansion and compression of the internal gas. Typically this is done by a carefully selected/designed piston-cylinder combination/pair. A glass cylinder with a matching graphite piston is an option. But this requires manufacture precision and procurement of special materials that most schools would likely not attempt. For the 3D printed LTD Stirling engine a printed polymer diaphragm has been developed and its optimization was attempted. We used finite-element analysis (FEA) to design the item and then tested it using a 3D printed model and a DAQ system. In this case we manufactured a load cell, using strain gauges on the rocker beam, Figure 4, to measure the spring and gas pressure loads being applied to the crankshaft. Following these projects, Caninvent 006, Figure 13, was designed specifically for education purposes. The bottom red container will be filled with hot water and the top cold. In this case the diaphragm forms the end of the cylinder. Ports and features have been added to the base design for attaching various sensors. DAQ systems can be pre-made and fitted or students can develop their own DAQ systems and write their own code.

Figure 13. CAD Render of Caninvent 006 LTD Stirling Engine for Education

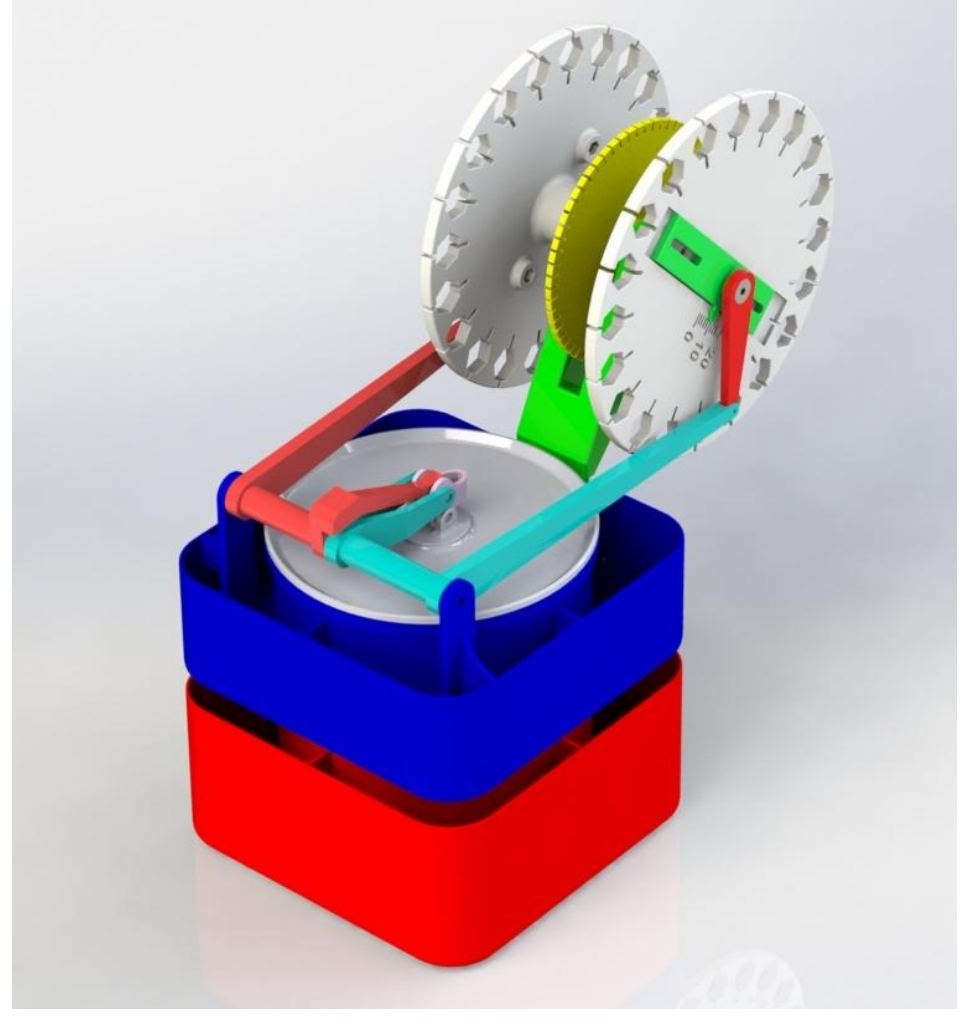

For these two projects the prime learning outcome for the student was to experience a research and development process using real mechanical devices as they could be easily, and quickly, made by AM. The alternative would be to design and make metal parts by conventional tools and by qualified technicians. In 
that case it would be impossible for the student to realize their designs and test their theories in a single semester.

\section{Creative Design}

One of the reasons the Stirling engine is so attractive to creative minds is its wide scope for inventing an infinite variety of designs. Internal combustion engines predominately use a slider crank with pistons and cylinders. The only competitor, which has had only limited commercial success, has been the Wankel Rotary engine (Hege, 2001). The Stirling engine, however, has three main configurations and the design variation potential within these is limitless. For example, some people design free piston engines that use no crankshaft, others use a Ringbom hybrid crank and free displacer design (Fedele, 1997). The WhisperGen $^{\mathrm{TM}}$ is based on a four cylinder double acting configuration using a wobble yoke mechanism (Clucas, 1994).

We have produced many variations of engines with some, most, or all parts made by additive manufacture. Our current collection is shown in Figure 14.

Figure 14. Collection of Fully and Mostly 3D Printed LTD Stirling Engines

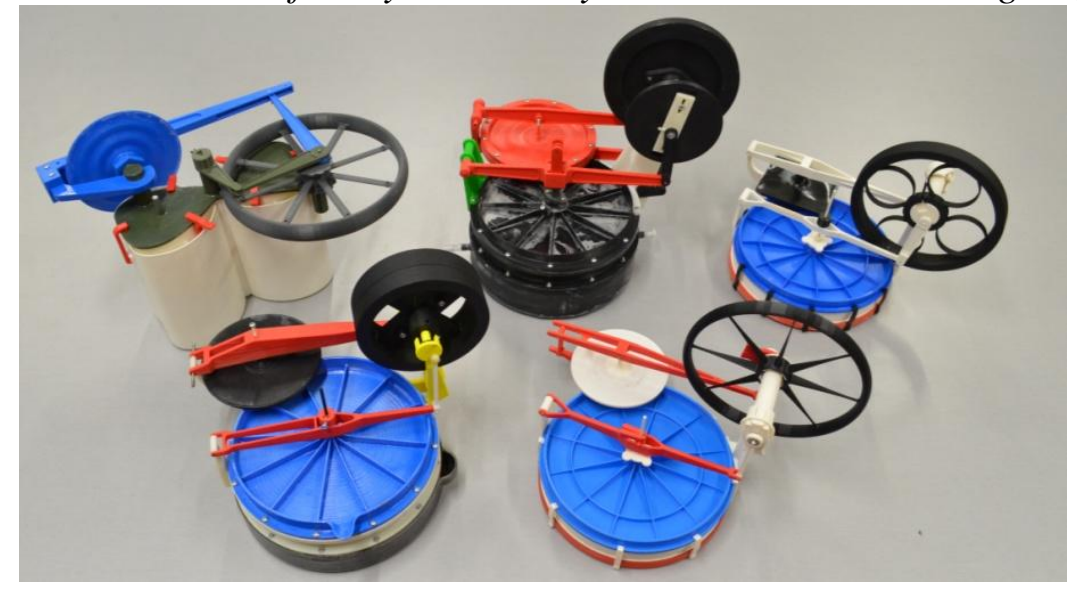

The files required to print one of these engines, bottom right, is available at

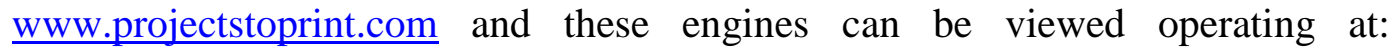
http://bit.ly/1Nmyx3R.

An example of applied creative design is the Bow Tie engine, shown in Figure 15. Minimizing friction losses is essential for good engine operation. Consequently, lack of attention to detail or poor part manufacture can result in an engine that will not operate. An attempt to address bearing friction loss led to the development of this engine which uses a 'spinning top' flywheel design and rotary oscillating displacer. 
Figure 15. Bow Tie Engine

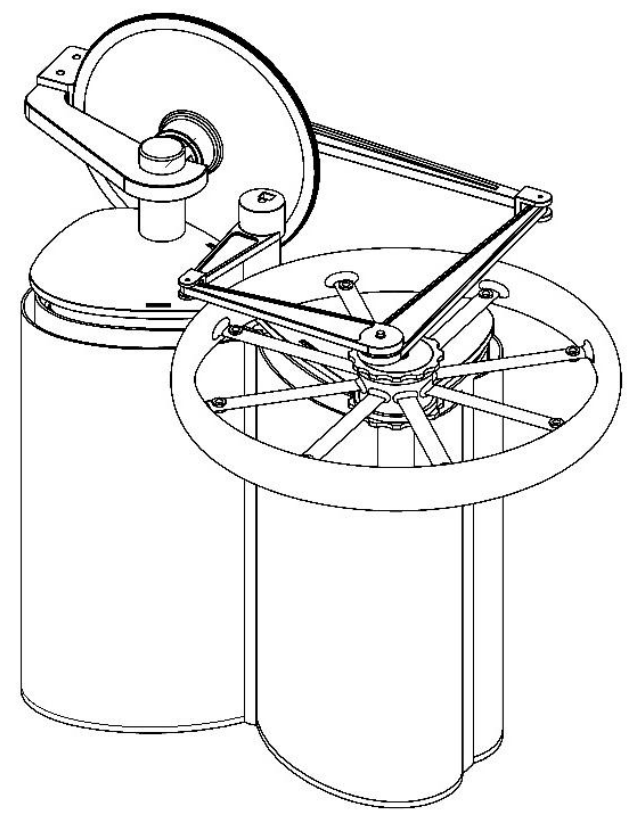

\section{Postgraduate Studies}

Thermodynamic analysis of the Stirling Engine is extremely complex. The working gas pressure, temperature, velocity and viscosity are in a state of flux over an entire engine cycle. (Hargreaves, 1991) Along with this the heat exchanger wall temperature changes due to the varying heat transfer rates. Many have worked on developing an accurate theory, simulation code and optimization routines to aid finding the optimum machine geometry (Clucas, 1994). It was often not possible to make the geometry that the simulations predicted would improve the engine due to the required special or impossible machining processes. Additive manufacture now allows making simple or highly complex heat exchanger geometry so the potential for engine performance optimization research has significantly expanded. Work has begun on developing an engine using 3D printed metal heat exchangers; the projects aim is to develop a 'super' optimized engine that is not limited by subtractive manufacture techniques (Clucas, 2014).

\section{Conclusions}

The combination of additive manufacture and the LTD Stirling engine offers many levels of engaged student education. Low 3D printing machine and material costs now enable teaching institutions to manufacture live demonstration equipment that can be used to teach thermodynamics, mechanics, dynamics, material properties, data acquisition and analysis. Using just hot and cold water as the energy source, health and safety concerns are significantly alleviated. 


\section{Acknowledgments}

Our special thanks go to Daniel Pugh and Tim van Ginkel, two students of the Department of Mechanical Engineering who have worked on the two ICOS topics as part of the BE Hons programme. The authors are also grateful for financial support from The University of Canterbury.

\section{References}

Blanck, M. (2014). EMTH271, Mathematical Modelling and Computation Canterbury, University. of. (2014). "LEARN." from http://learn.canterbury.ac.nz/.

Clucas, D. (1994) Development of a Stirling Engine Battery Charger Based on a Low Cost Wobble Mechanism. PhD, University of Canterbury, Christchurch, New Zealand.

Clucas, D. M. (2014) Additive Manufacture of a Working Engine. RAPID Conference and Exposition Detroit, MI, USA.

Crump, S. S. (1992). Apparatus and Method for Creating Three-Dimensional Objects. U. S. Patent. USA, Stratasys, Inc.

Fedele, L., and Dong, W. (1997) Design of the ULS-RSE Ringbom-Stirling Engine. International Stirling Engine Conference and Exhibition Ancona Italy.

Gaynor, P., Webb, R., Caleb, L. (2008). Low Temperature Differential Stirling Engine Based Power Generation. ICSET 2008, IEEE.

Gutschmidt, S. (2014). "ENME 203, Dynamics and Vibration." from http://bit.ly/ 1QpTaQr.

Hargreaves, C. M. (1991). The Philips Stirling Engine. Elsevier.

Hege, J. (2001). The Wankel Rotary Engine: a history. McFarland and Company.

Huang, Y. a. L., M., Mazunder, J. and Donmez, A. (2015). "Additive Manufacturing: Current State, Future Potential, Gaps and Needs, and Recommendations." Journal of Manufacturing Science and Engneering, 28.

Jones, F. (2007). The effect of a high temperature high pressure nitrogen environment with carbonaceous impurities on the performance of three austenitic alloys.' Masters Thesis University of Canterbury.

Kongtragool, B., Wongwises, S. (2003). A review of solar-powered Stirling engines and low temperature differential Stirling engines. Renewable and Sustainable Energy Reviews. Elsevier Science.

Myszka, D. H. (2012). Machines and mechanisms: Applied kinematic analysis. Boston, Prentice Hall.

Newton, I. (1687). Philosophiæ naturalis principia mathematica. Londini, Jussu Societatis Regiæ ac Typis Josephi Streater. Prostat apud plures Bibliopolas.

Senft, J. R. (1991). An ultra low temperature differential Stirling engine. Fifth International Stirling Engine Conference. Dubrovnik, Inter University Centre.

Watanabe, T., Kubo, I. (2007) Development of an Advanced Stirling Engine Generator for Solar Application. $13^{\text {th }}$ International Stirling Engine Conference Tokyo, Japan. 
